\title{
Empirical Study on B-S Model Based Pricing of Warrants in China
}

\author{
—With Calculation of Standard Deviation by Modified EMA Model
}

\section{Zhaoyuan Geng, Qi Ding, Junchi Zhang}

Department of Applied Economics, Business School of Zhejiang University City College, Hangzhou, China.

Email: gengzy@zucc.edu.cn

Received 2013

\begin{abstract}
This article valuated theoretical prices of covered warrants in china through fitting temporal series of target warrant prices and market information of corresponding underlying securities. Furthermore, the author surveyed the deviation between market price and theoretical price of warrant. In order to eliminate the inaccuracy caused by constant volatility assumption of B-S Model, the author creatively used Modified Exponentially Moving Average (Modified EMA) Model to calculate the historical volatility of market prices of warrants and fixed the best dilution factor through Grid Search Technique. Also, validities of calculation of historical volatility by Modified EMA Model and original EMA Model are compared. Original data came from market information during the period 2005-2008 supported by security trading software and calculation was done via Excel. At the same time when Chinese government was going to revive covered warrant market, this article provided a more accurate method of pricing covered warrant, also known as modified B-S Model.
\end{abstract}

Keywords: Warrant Pricing; Covered Warrant; B-S Model; EMA Model; Grid Search Technique

\section{Introduction}

Pricing warrant has been researched a lot in abroad, which has perfect pricing theory system and with B-S model for the main body of the effective measurement method system [1]. Black-schoals (B-S) model overcomes the limitations of the study of early scholars, providing the stock options and warrants pricing methods reliably. While the study in China is still developing, lacking correction of own assumptions of B-S model. In the background that Chinese government was going to revive covered warrant market, the author creatively puts forward Modified Exponentially Moving Average (Modified EMA) Model to measure the volatility of the asset, fixed B-S model's constant volatility assumptions, and get the more suitable model of pricing covered warrants for China.

\section{Model Construction}

The article aims to construct an accurate pricing method of covered warrant, which essentially is a Modified Black-Scholes (Modified B-S) Model.

The formula of Original Black-Scholes (Original B-S) Model as shown below:

$$
\left.C(S, T)=S N d_{1}\right)-K_{e}^{-r t} N\left(d_{2}\right)
$$

$$
\begin{gathered}
d_{1}=\frac{1}{\sigma \sqrt{T}}\left[\ln \frac{S}{K}+\left(1+\frac{1}{2} \sigma^{2} T\right)\right] \\
d_{2}=d_{1}-\sigma \sqrt{T-t}
\end{gathered}
$$

where $\mathrm{C}(\mathrm{S}, \mathrm{T})$ : the value of European call option;

S: present price of underlying assert;

T: Due date of warrant;

$\mathrm{K}$ : striking price of option;

$\mathrm{r}$ : he risk-free rate of rate of the investment due in $\mathrm{T}$;

$\sigma$ : the annual volatility of the price of underlying assert;

$\mathrm{N}(\mathrm{x})$ means cumulative probability distribution function of standard normal distribution variable [2].

The pricing object in this article is the Chinese covered warrant, which can be seen as a typical European call option, so it is reasonable to use the original B-S Model. However, the rigorous limitations attached to the original B-S Model on the financial market, underlying asserts and the characteristics of the option have affected the accuracy of the pricing to different degrees [3]. Therefore, this article is to amend this model.

Apart from the Behavioral Financial, almost all the pricing models in the spin-off pricing have included the perfect market hypothesis, so the improvement in terms 
of the prerequisite hypothesis of the financial market is impractical.

Then the solely necessary and feasible amendment lies on the prerequisite hypothesis of the underlying assert. Evidences have accumulated to show that the deviation caused by the share profits prepayment hypothesis is not significant, and furthermore the covered warrant itself does not produce the shareholding dilution effect, so the amendment of the shareholding dilution effect can be excluded. Upon this, the article has finally chosen the constant volatility rates hypothesis as the breach to amend the original B-S Model.

In order to amend the constant volatility hypothesis of B-S Model, the author creatively used Modified EMA Model to calculate the volatility of yield of underlying warrants. EMA (Exponentially Moving Average) is a dynamic statistic, which essentially is a predictive value by adding observations in the past and giving longer value a lower weightings coefficients [4]. Original EMA Model supposes the yield of underlying assert obeying Gaussian distribution $-R_{t} \sim N\left(0, \sigma^{2}\right)$, the formula as shown blow

$$
\begin{gathered}
\sigma_{0}=\sqrt{\frac{\sum(R-\mu)^{2}}{n-1}} \\
\sigma_{t}^{2}=(1-\lambda)\left(R_{t-1}-\mu_{t-1}\right)^{2}+\mu \sigma_{t-1}^{2}
\end{gathered}
$$

where $\sigma_{t}$ : the volatility of the $\mathrm{t}$;

$\lambda$ : dilution factor $(0<\lambda<1)$;

$\mu$ : average yield rate in sample periods;

$R_{t-1}$ : the yield rate in the t-1 [5].

SIAH Continuous Information Connecting Hypothesis indicates that Volatility has a positive correlation with volume. Based on this hypothesis, Rong He amended EMA Model in 2009. The formula as shown blow:

$$
\sigma_{t}^{2}=\gamma V_{L}+(1-\lambda)\left(R_{t-1}-\mu_{t-1}\right)^{2}+\mu \sigma_{t-1}^{2}
$$

where $\gamma$ is constant coefficient;

$V_{L}$ is the long-period volatility of the yield rate of warrant.

According to the two theory models above, the author has deduced a more accurate pricing method of covered warrant used in this article, the modified B-S Model. Using the modified EMA Model to calculate $\sigma_{t}$, and supposing $n=60$, which means using the standard deviation 60 trading days before the opening day of the sample term as the original volatility $\sigma_{0}$, one can get the final $\sigma$ used in the modified B-S Model.

\section{Analysis of Chinese's Data Warrants Based on Empirical}

\subsection{Data's Selections}

This evidence in the article is used in Time-series data, including Angang JTC1, Wuliang YGC1 and Yage QCB1 three Covered Warrants' price data from the opening to the delisting and the corresponding underlying stock price data.

In addition to warrants and the price of the underlying asset, B-S Model also requires Risk-free Interest Rate over the same period. This article uses the 7-Day Bond Repurchase Rate instead of the Risk-free Interest Rate, the data logger for details sees appendix A.

\subsection{Real Diagnosis Examination}

1) Determination of Attenuation factor $\lambda$.

In order to determine the best attenuation factor value, this article uses the Grid Search Technique, $\lambda$ value is $0.1,0.5,0.8$ and 0.95 carry on the pilot calculation separately. According to the definition, the best attenuation factor must make the theoretical price and the market price cumulative departure is smallest, also namely realizes $\min \left\{\sum_{i=1}^{T}\left(C_{i}-P_{i}\right)^{2}\right\}, P_{i}$ is the market price, $C_{i}$ is the theoretical price. The result compiles see Table 1: $\lambda=0.95$

2) Modified EMA Model validity examination

In order to check the Modified EMA Model's validity, this article has compared three sign stock income fluctuation rate separately under the Modified EMA Model and the Original EMA Model measurement cumulative departure. It compiles the result to reference Tables 1 and 2:

The result demonstrates, in all four pricing of warrants estimate, uses the Modified EMA Model to measure the sign stock income fluctuation rate forms price accumulation deviation is smaller than EMA Model. Obviously, the Modified EMA Model has achieved the anticipated effect, this has also guaranteed this article validity, which revises to the Modified B-S Model.

Table 1. Modified EMA Model accumulation price deviation table.

\begin{tabular}{ccccc}
\hline & $\lambda=\mathbf{0 . 1}$ & $\lambda=\mathbf{0 . 5}$ & $\lambda=\mathbf{0 . 8}$ & $\lambda=\mathbf{0 . 9 5}$ \\
\hline Angang JTC1 & 97.942 & 95.965 & 95.985 & $95.013^{*}$ \\
Wuliang YGC1 & 1595.977 & 1596.124 & 1595.823 & $1595.299 *$ \\
Yage QCB1 & 362.917 & 350.266 & 344.466 & $327.194^{*}$ \\
\hline
\end{tabular}

Note: ${ }^{*}$ is the accumulation deviation the most minor term.

Table 2. Original EMA Model accumulation price deviation table.

\begin{tabular}{ccccc}
\hline & $\lambda=\mathbf{0 . 1}$ & $\lambda=\mathbf{0 . 5}$ & $\lambda=\mathbf{0 . 8}$ & $\lambda=\mathbf{0 . 9 5}$ \\
\hline Angang JTC1 & $369.924 *$ & 370.948 & 372.923 & 375.016 \\
Wuliang YGC1 & 1791.567 & 1796.074 & $1784.153^{*}$ & 1809.885 \\
Yage QCB1 & $553.957^{*}$ & 576.433 & 603.248 & 625.416 \\
\hline
\end{tabular}

Note: ${ }^{*}$ is the accumulation deviation the most minor term. 
3) Modified B-S Model estimate rational examination

In rational examination part, this article recognizes the information of three warrant stocks and sign stock price to Modified B-S Model, and obtains the theory price of each warrant B-S model. In order to guarantee the integrity of the demonstration, the author retained four warrants in the estimate process separately from opening to the drawing all trading day data.

The key points of this part are the quota examination revises, the validity of Modified B-S Model in our country warrant exchange market. Chart $1-3$ visually show bias and fit of the three warrants market price and theoretical price of the B-S Model:

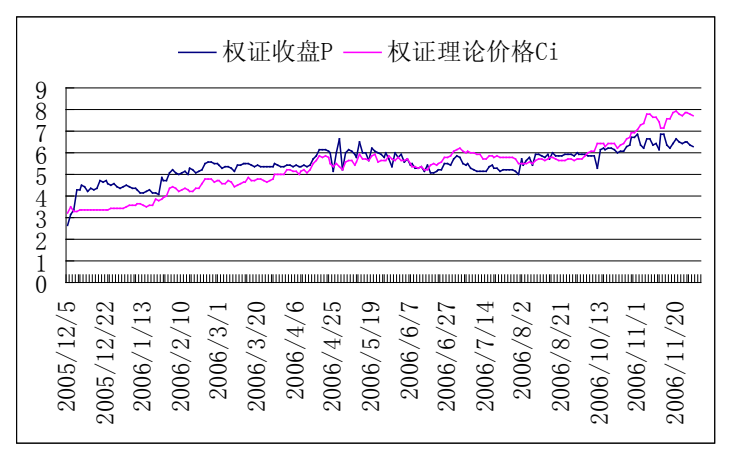

Figure 1. Angang JTC1- Market price and theoretical price comparison chart.

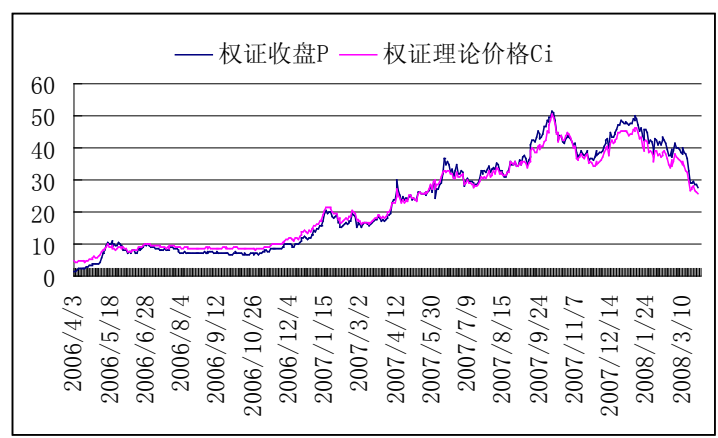

Figure 2. Wuliang YGC1-Market price and theoretical price comparison chart.

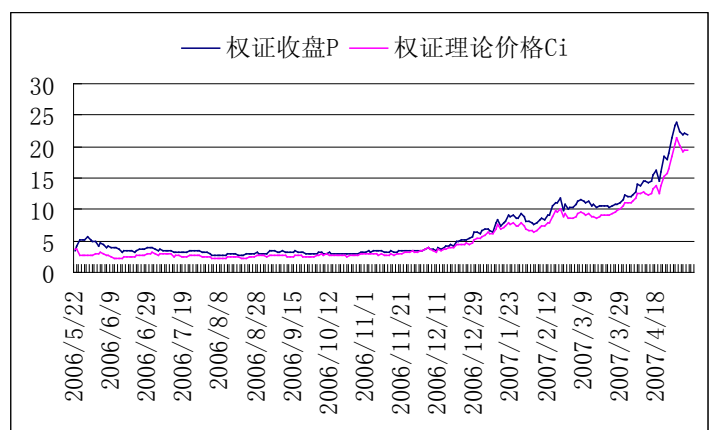

Figure 3. Yage QCB1-Market price and theoretical price comparison chart.
In order to verify the validity of pricing, this article has calculated in the entire sample period various warrant market prices and between the B-S model theory price deviation, and establishes the reasonable deviation range is $\pm 5 \%$. The concrete computational method is: Dif $=$ $\left(P_{i}-C_{i}\right) / C_{i}$, Dif is a deviation, $P_{i}$ is the market price, $C_{i}$ is the theoretical price. The statistical result sees Table 3.

The result showed that three warrant price overall deviation besides "Yage QCB1" in $\pm 5 \%$, indicates the market price close theoretical price. The sample whole's average degree of deviation is $7.24 \%$. Certainly, "Yage QCB1" surpasses 20\% degree of deviation is not allowed to neglect. Its positive number's large-scale deviation indicated that its market value is higher than the B-S Model theory value obviously.

4) The empirical analysis result

The outcome shows there are some partial differences between the modified B-S Model and market price of covered warrants in China, in addition, market price is always higher than theoretical price. The author considers the major reason why warrant price is estimated is that excess liquidity and excessive speculation in warrant market.

The article used domestic warrant market compares with internal stock market and foreign warrant market, the fluidity of our domestic warrant market is obviously too high. In Table 42006 years of data, for example, have at least the number of issued to the mainland market created all trade authority card of authority card is the largest turnover. This high liquidity is probably authority card products are the main cause of market overestimate. And Xiao Gang in the 2007 study also confirmed the warrant and its underlying stock warrants size and liquidity will have a significant impact on pricing.

As China's warrants market, one of the rare financial derivatives, along with the reform and open of authority card is investors' attention. In addition to rational factors, investors' "Herding Effect" can also explain the overestimation of the phenomenon. In China, small investors, individual investors accounted for the majority of warrants. Their limited financial knowledge to simply be the expected future market ups and downs as the main factors affecting the price of warrants, and this study marks the 2005-2008 bull market in the domestic stock market, market expectations for the future generally optimistic. This optimism is expected to bring the warrants will result in heat in this part of the study warrants be overestimated.

Table 3. Market price and theoretical price deviation table.

\begin{tabular}{ccccc}
\hline $\begin{array}{c}\text { Covered } \\
\text { Warrant }\end{array}$ & $\begin{array}{c}\text { Angang } \\
\text { JTC1 }\end{array}$ & $\begin{array}{c}\text { Wuliang } \\
\text { YGC1 }\end{array}$ & $\begin{array}{c}\text { Yage } \\
\text { QCB1 }\end{array}$ & Average \\
\hline Dif & $4.85 \%$ & $-4.35 \%$ & $21.23 \%$ & $7.24 \%$ \\
\hline
\end{tabular}


Table 4. The world's major market trading information summary warrants.

\begin{tabular}{cccccccc}
\hline Exchange & $\begin{array}{c}\text { The end of the total } \\
\text { number of covered } \\
\text { warrants in circulation }\end{array}$ & Turnover (USD) \\
\cline { 2 - 7 } & $\mathbf{2 0 0 5}$ & 2006 & 2007 & 2005 & 2006 & $\mathbf{2 0 0 7}$ \\
\hline $\begin{array}{c}\text { Australian Stock } \\
\text { Exchange }\end{array}$ & 2,447 & 3,019 & 4,028 & 4,985 & 7,311 & 17,428 \\
$\begin{array}{c}\text { Malaysia Stock } \\
\text { Exchange }\end{array}$ & 12 & 33 & 120 & 277 & 934 & 3,843 \\
$\begin{array}{c}\text { Hong Kong Stock } \\
\text { Exchange }\end{array}$ & 1,304 & 1,959 & 4,614 & 110,168 & 23,411 & 610,380 \\
$\begin{array}{c}\text { Korea Stock } \\
\text { Exchange }\end{array}$ & 72 & 1,387 & 1,646 & 41 & 43,689 & 73,039 \\
$\begin{array}{c}\text { Singapore Stock } \\
\text { Exchange }\end{array}$ & 455 & 521 & 883 & 6,521 & 9,156 & 19,594 \\
$\begin{array}{c}\text { Taiwan Stock } \\
\text { Exchange }\end{array}$ & 540 & 694 & 2,085 & 4,424 & 5,388 & 7,717 \\
$\begin{array}{c}\text { China Stock } \\
\text { Exchange }\end{array}$ & 4 & 26 & - & 21,548 & 243,900 & - \\
\hline
\end{tabular}

Source: World Federation of Exchange Annual Report (2005-2008)

\section{Conclusion}

The paper is based on B-S model for warrants and measurement asset price volatility after adjusting the EMA Model to build a pricing covered warrant which is known as modified B-S Model. Evidence can be seen through the entire process, use Modified EMA Model to the market price of the asset of mark of volatility estimates that a good results. However, Modified B-S Model used in Chinese covered warrants on the theory of measurement to get the price and the actual market prices deviate from the remains. But such cases by the market structure, a specific period of optimism explained. Most of authority card effective pricing made by Modified B-S Model will be an optimization scheme in China.

This article argues that there should continue to study the following two questions: First, the duration of warrants priced deviations in different periods of comparison. Second, the market liquidity will affect the warrant prices. So such research will lead to the warrants pricing system in China more perfect.

\section{Acknowledgment}

This paper is supported by the construct program of the key laboratory in Hangzhou.

\section{REFERENCES}

[1] Liang Guoliang2004 Financial economics (Taipei: Five Southern Book Publishing Co., Ltd.) pp 256.

[2] Black F 1973 Scholes M. The Pricing of Options and Corporate Liabilities.Journal of Political Economy, (81): 637-659.

[3] Wei Guqianfengyan 2005 Details of the Black-Scholes Model (Taipei: Ding Mao Press) pp 32-36.

[4] Bai Shuangmei, Du Fuzhou 2010 Control chart parameter optimizes based on Markov chain's EWMA and realizes. Manufacturing industry automation. (6): 64-67.

[5] Wang Haiyu, Xu Jichao, Yang Jiafeng, Chang Guangshu 2006 APL-based optimal design of EWMA chart. Systems engineering theory method application.15(1): 65-70. 